\title{
Physiological studies of Helminthosporium Pathovars Isolated from Infected Maize Plant in the Region of Karnataka
}

\author{
Soumya $C^{1}$, Dr Y L Ramachandra ${ }^{2}$ \\ ${ }^{1}$ Department of Biotechnology, Sapthagiri collage of Engineering, Bangalore \\ ${ }^{2}$ Department of Bioinformatics and Biotechnology, Kuvempu University, Shankerghatta
}

\begin{abstract}
Karnataka is one of the potential maize producing regions in India. Therefore maize in this region has the potential to become diseased under certain conditions. Diseases of crops can affect plant physiological activities, yield and/ or quality of the harvested commodity which can impact profitability and increase the risks of farming. Disease management is one of the major problems faced by farmers, and this has become a big threat and made farmers to become risk adverse to invest in farming as a business. This study is about to determine suitable culture conditions such as different culture media, optimum temperature, pH, carbon source were optimized to culture Helminthosporium in laboratory conditions to do characterize the gene for pathogenicity. Among all the media the best media were found to be the MRBA and PDA. It was found to be the optimum temperature and $\mathrm{pH}$ were $20^{\circ} \& 25^{\circ}$ and $\mathrm{pH}$ of $5 \& 6$. Carbon source for the optimum growth was selected by growing in different carbon sources. It was revealed that best carbon source found to be starch for better growth of colonies. Along with these parameters, toxin study of the Pathogen was done. The crude phytotoxic was extracted from culture filtrate using methanol and chloroform.TLC revealed the presences of toxin in crude extract.
\end{abstract}

Keywords: Helminthosporium pathovars, pathogenicity, temperature, $\mathrm{pH}$, carbon source

\section{Introduction}

Maize (Zea mays. L) Is regarded as the queen of cereals due to its high yield efficiency. Maize is the third most important food grain in India next to wheat and rice. Despite its high yield potential, one of the major limiting factors of maize grain yield is its sensitivity to several biotic stresses especially the diseases. According to some record about 65 pathogens infects maize and of these maydis leaf blight or southern corn leaf blight is considered as one of the serious disease the extent and severity of MLB disease varies from season to season. In worm $\left(20-32^{\circ} \mathrm{C}\right)$ and moderately humid environment of the world, maydis blight is potentially damaging and may cause significant yield losses (Thomson and bergquest 1984). Southern corn leaf blight (SCLB) is an important foliar disease of maize crop and caused by fungi

Helminthosporium (Cochliobolus heterostrophus), and also known as (Anamorphs Bipolaris maydis or ascomycetes, Helminthosporium maydis) but for the sake of brevity we will refer to all of these as Helminthosporium. It is reportedfrom most maize growing regions but most devastating in hot and humid tropical and temperate areas of the world. Almost $70 \%$ yield loss is recorded due to SCLB (Kump.et.al 2011). No known genes confer complete immunity to this disease; instead, maize breeders rely on polygenic, quantitative resistance to SCLB (Holley and Goodman 1989). Three races of C. heterostrophus known as O, T and C have been identified to date (Smith et.al 1970). Race $\mathrm{O}$ is considered to be the most common race in most areas and is controlled by nuclear genes. Race T, the cause of the 1970s epidemic inNorth America, is specific to maize containing Texas male-sterile cytoplasm (cms-T) and is controlled mainly by cytoplasmic factors. The most prominent difference between race $\mathrm{O}$ and $\mathrm{T}$ is that race $\mathrm{O}$ only attacks leaves while race $\mathrm{T}$ attacks leaves, stalks, leaf sheaths, ear husks, ears and cobs. Race $\mathrm{C}$ is a cms-C cytoplasm-specific race reported only in China (Wei.et.al 1988).Karnataka is one of the potential maize producing regions in India. Therefore maize in this region has the potential to become diseased under certain conditions. Diseases of crops can affect plant physiological activities, yield and/ or quality of the harvested commodity which can impact profitability and increase the risks of farming. Disease management is one of the major problems faced by farmers, and this has become a big threat and made farmers to become risk adverse to invest in farming as a business. It is also one of the factors leading to yield reduction; southern corn leaf blight is one of the prone fungal diseases in maize. Therefore it is important to carry out a study on prevalence of southern corn leaf blight pathogen of maize in Karnataka.

\section{Materials and Methods}

\section{Pathogen culture}

The youngest fully expanded mature leaves from zea mays were harvested, washed and dried on the paper towel. Leaf disks of $20 \mathrm{~mm}$ diameter were exercised carefully with needle from leaf samples. The leaf disks were placed immediately in Petri plates containing SDA/PDA media. Petri plates were placed in growth chamber maintained at $25^{0} \mathrm{C}$ for 2-3 days. Mixed cultures were obtained. Helminthosporiun pathovars was grown on SDA media and cultured for about 48 hours the culture was grown which results in mixed culture. And it is screened for the presence of Helminthosporium pathovars it was sub cultured to obtain pure culture. The pure culture was isolated and identified by using microscope by lacto phenol staining method.

\section{Effect of Different media for colony growth}

The effect of culture conditions including media, incubation temperature, carbon source and $\mathrm{pH}$ were observed on growth of 


\section{International Journal of Science and Research (IJSR) \\ ISSN (Online): 2319-7064 \\ Index Copernicus Value (2015): 78.96 | Impact Factor (2015): 6.391}

pathogen Helminthosporium. Different media such as Potato Dextrose Agar, Sabouraud Dextrose Agar, Martin Rose Bengal Agar, Soil Extract Agar and SpeziellerNahrstoffarmer agar. Each day the growth of mycelia was measured and was compared.

\section{Optimal temperature for the growth of Helminthosporium Pathovars}

To determine the most suitable optimum temperature for the growth of Helminthosporium pathovarscultures were grown on SDA and SEA at different temperatures viz., 30 degrees, 40 degrees, 50 degrees. The colony diameter of the pathogen temperature was recorded at $3 \mathrm{rd}$, 5th, 7th days during incubation period.

\section{Optimal pH for the growth of Helminthosporium Pathovars}

For Suitable optimum $\mathrm{pH}$ for the growth of Helminthosporium pathovars. The subcultures were grown on SDA and SEA at $\mathrm{pH}$ $3,4,5,6,7$ and 8 by addition of $\mathrm{NaOH}$ and $\mathrm{HCl}$. The colony diameter of the pathogen $\mathrm{pH}$ was recorded at $3 \mathrm{rd}$, 5th, 7 th days during incubation period.

Effect of Different carbon Source for the growth of Helminthosporium pathovars

Carbon source for the growth of Helminthosporium pathovars. The subcultures were grown on media containing different carbon sources like Lactose, Maltose, Galactose and fructose. The colony diameter of the pathogen carbon source was recorded at $3 \mathrm{rd}$, 5th, 7 th days during incubation period.

\section{Toxin study of Helminthosporium pathovars}

Potato dextrose broth was prepared and the spores grown on MRBA media was used for inoculation, as there was rapid growth in MRBA. The broth was incubated at room temperature for 15 days, for the development of the suspension culture. The suspended culture was filtered using whattman's filter paper no. 42 to obtain filtrate. The obtained filtrate was centrifuged $3000 \mathrm{rpm}$ for 20 minutes. Clear supernatant solution was collected in a clean sterile conical flask and pellet sediment at the bottom of the centrifuge tube was discarded. Clear supernatant solution served as a sample of crude toxin preparation. The crude toxin was partially purified with ammonium sulphate sterile uninoculated PDA at 1:2 ratios. Toxin spray and injection were used for bioassay of toxin; the leaves were observed for symptoms development after 24 hours of treatment. A control of PDB kept for each treatment. Two methods were employed for the toxin study of Helminthosporium
Spray method: The extracted toxin of $1 \mathrm{ml}$ was sprayed using a sprayer on to two weeks old maize plant. $1 \mathrm{ml}$ of PDBwas sprayed on maize leaf which is used as control. The leaves were observed for symptoms development after 24 hours of treatment.

Pin prick method: Ten ball pins were tied together using a rubber band and leaves of two weeks old Maize plant werepricked. The extracted toxin of $1 \mathrm{ml}$ was sprayed using a sprayer where $1 \mathrm{ml}$ PDB was used as a control. The leaves were observed for symptoms development after 24 hours of treatment.

\section{Toxicity of crude extract forThin Layer Chromatography (TLC)}

\section{Extraction of toxin}

The culture filtrate and control (PDB) was concentrated to $10 \%$ of its original volume by using a flash evaporator at $50^{0}$ C.An equal volume of Methanol was added to the concentrated solution, and then extracted by chloroform (Double theamount of Methanol). The chloroform layer was separated in a separation funnel. The extraction with chloroform was repeated twice. The combined chloroform layers were evaporated at room temperature. $3.6 \mathrm{ml}$ of dark brownish semi solid crude extract was obtained. The crude extract was dissolved in $2 \mathrm{ml}$ of Methanol to have a $10 \%$ toxin solution. $1 \mathrm{ml}$ of extraction used as a sample for TLC. $2.5 \mathrm{ml}$ of control was obtained and it was dissolved in $1 \mathrm{ml}$ of Methanol to have a $10 \%$ of control solution. $1 \mathrm{ml}$ of control extract used as a control For TLC. TLC was employed using microscopic slides and $20 \times 10 \mathrm{~cm}$ glass planes with silica gel, without florescent indicators. $10 \mu \mathrm{l}$ of crude toxin extract was applied in duplicates on slides and developed using different combinations of chloroform: Methanol solvent system (5.0:5.0; 5.5:4.5; 6.0:4.0; 6.5:3.5; $7.0: 3.0 ; 7.5: 2.5 ; 8.0: 2.0 ; 8.5: 1.5 ; 9.0: 1.0)$. The $\mathrm{R}_{\mathrm{f}}$ was calculated by using the formula below,

\section{$R_{\mathrm{f}}=$ Distance $(\mathrm{cm})$ travelled by the solute from the origin Distance $(\mathrm{cm})$ travelled by the solvent from the origin}

\section{Results}




\section{International Journal of Science and Research (IJSR)}

ISSN (Online): 2319-7064

Index Copernicus Value (2015): 78.96 | Impact Factor (2015): 6.391

Graph 1

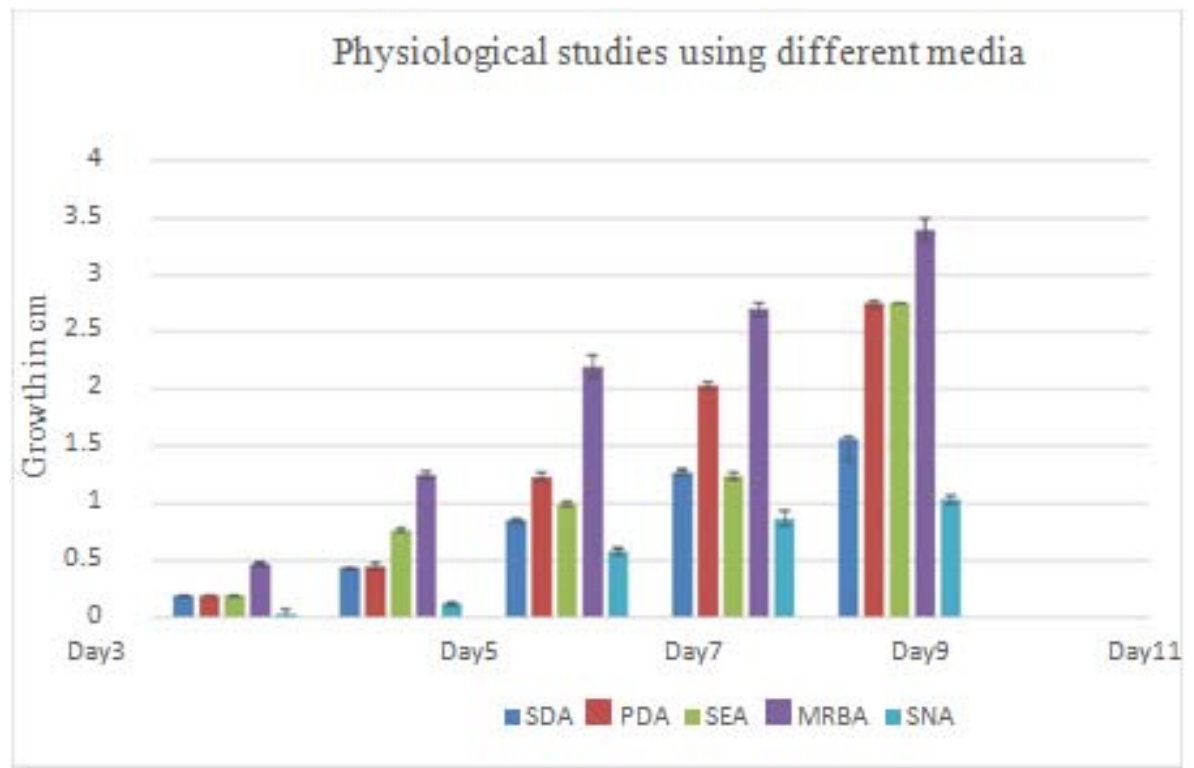

Effect of Different media for colony growth

Graph 2

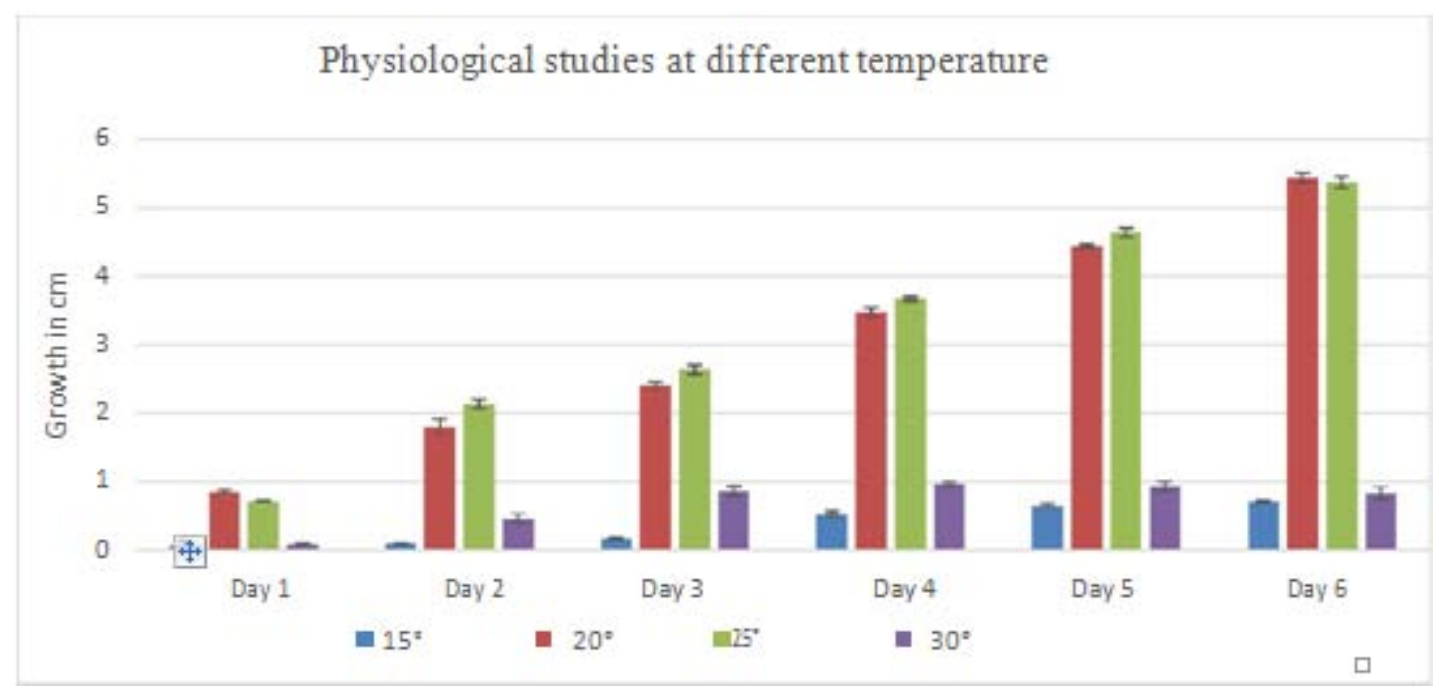

Optimal temperature for the growth of Helminthosporium Pathovars

Graph 3

Volume 6 Issue 1, January 2017

www.ijsr.net

Licensed Under Creative Commons Attribution CC BY 
International Journal of Science and Research (IJSR)

ISSN (Online): 2319-7064

Index Copernicus Value (2015): 78.96 | Impact Factor (2015): 6.391

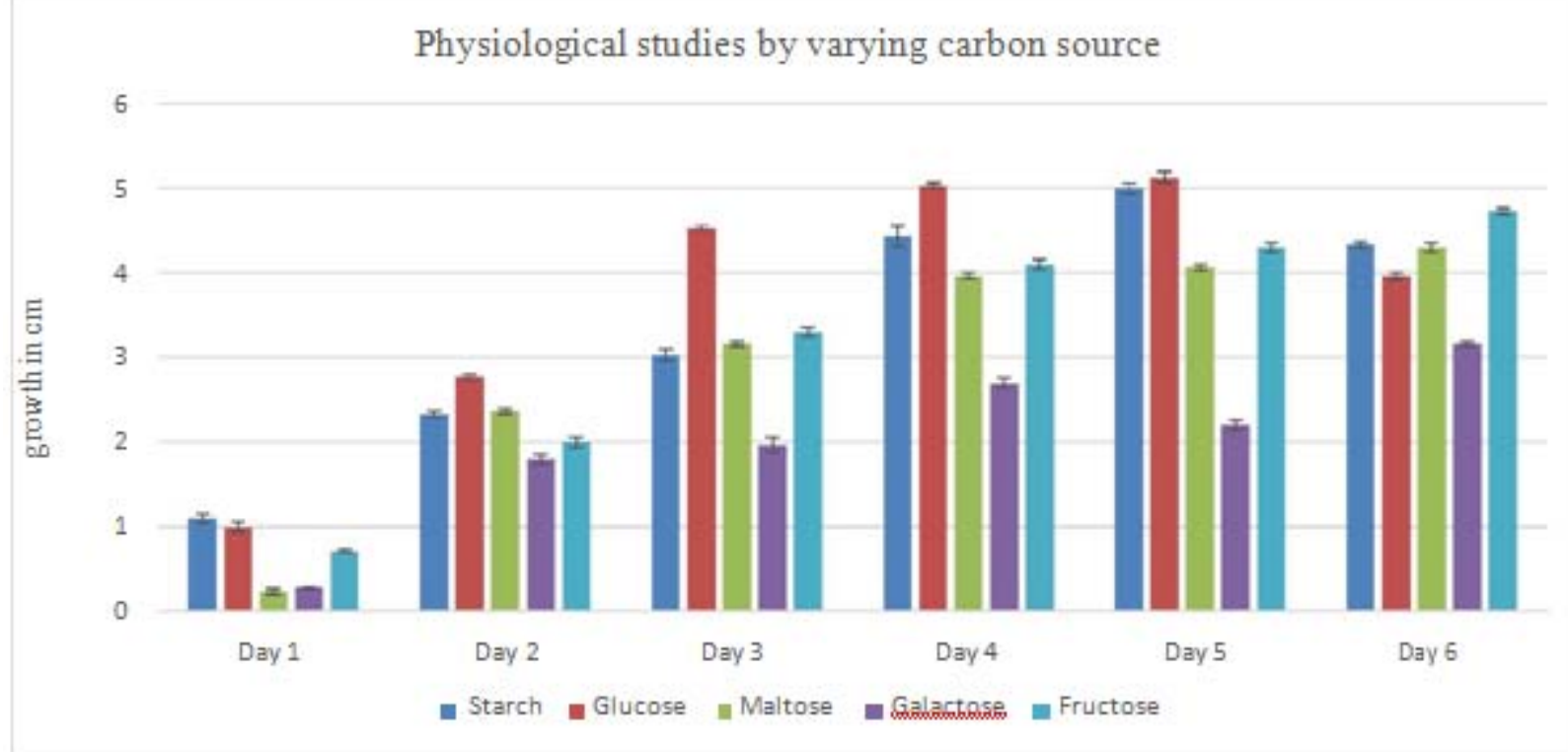

Suitable carbon sourcefor the growth of Helminthosporium Pathovars

Graph 4

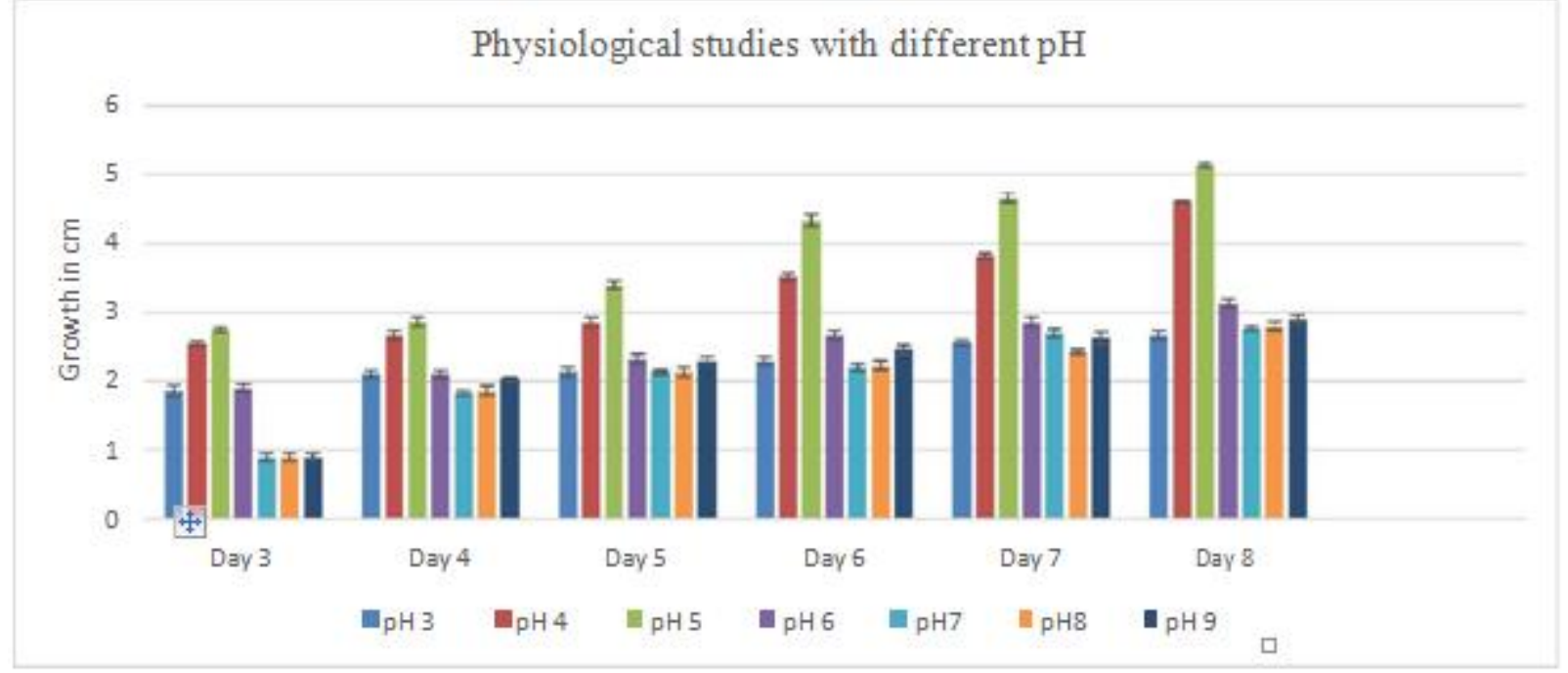

Different pH for the growth of Helminthosporium pathovars

\section{Figure 1}

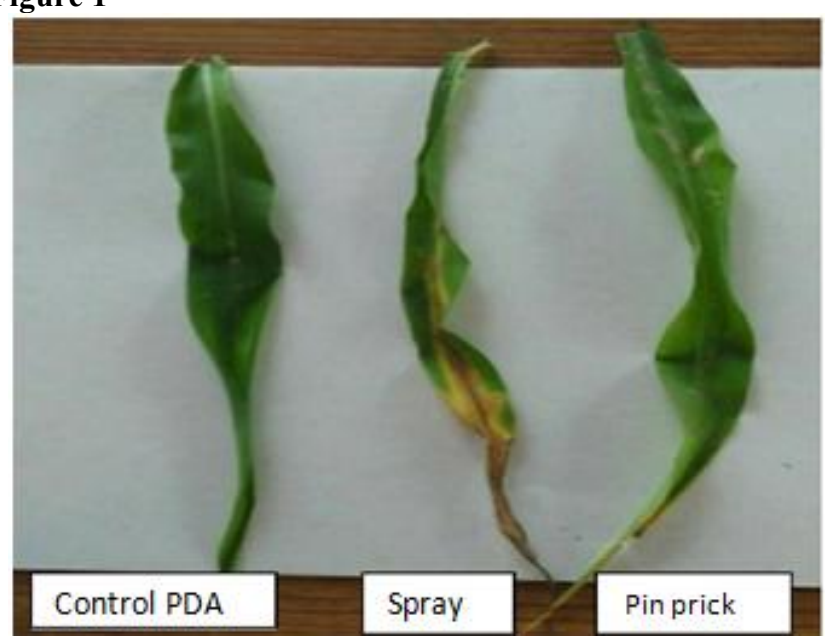

Toxin studies using Spray and pin prick method
Figure 2

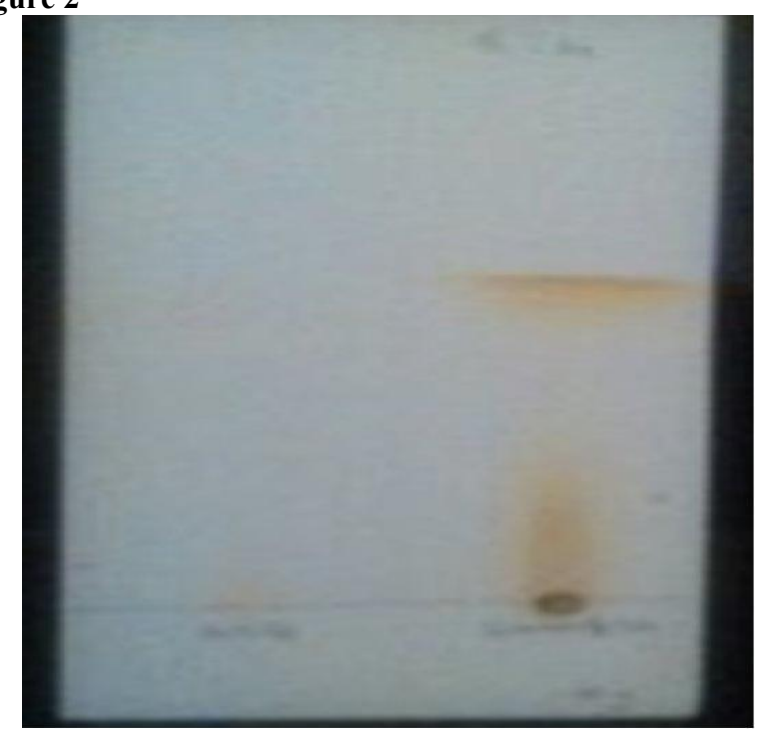

TLC (Solvent ratio 6.0:4.0)

Volume 6 Issue 1, January 2017

www.ijsr.net

Licensed Under Creative Commons Attribution CC BY 


\section{International Journal of Science and Research (IJSR) \\ ISSN (Online): 2319-7064 \\ Index Copernicus Value (2015): 78.96 | Impact Factor (2015): 6.391}

\section{Discussion}

Investigation of different growth media used for determining suitable nutrient for the growth of Helminthosporium for mass production from culture media (Gao and Liu 2010). The results of present investigation shows that most supporting media for the growth of the Helminthosporium pathovars was found to be MRBA and PDB.Two media i e PDA And Richard's agar proven best for the growth of C.heterostrophus with highest colony growth in studies conducted by Kumar et.al (Kumar and Rani 2009).However Amin Et.al used PDA for isolation and screening of fungal endophytes isolates against pathogen(Amin et.al 2012).Didvania et.al also used PDA fallowed by malt extract for maximum growth of mycelia and sporulation(Didvania et.al 2012). The Helminthosporium pathovars from pure culture grown on PDA at different temperature $20^{\circ}, 25^{\circ}, 30^{\circ}$ and $35^{\circ}$.From investigation $20^{\circ}$ and $25^{\circ}$ after seven days of incubation was found to be most suitable temperature for the mycelia growth and sporulation. Similar results are also reports Wallin and Loonan(1977).Chandwani and Munjal and Misra\&singh also observed the best growth was observed at $25^{\circ}$ after seven days of incubation (1963). Present investigation also conducted on Carbon source, $\mathrm{pH}$ and toxins. Glucose and starch was proven to be best carbon source for the maximum growth of mycelia when compared to maltose, galactose and fructose. Glucose is a common source for fungal growth.starch was also utilized as a major carbon source for the growth of H.gramineum proven by Chandwani\&munjal in their studies (1963).pH to be considered as a parameter for the growth it was observed from present studies that $\mathrm{pH} 5 \& 6$ was found to be most suitable for maximum growth of mycelia after seven days of incubation. Singh and singh also obtained the similar results of growth of H.Maydis at pH 5-7 respectively (1966). Phytotoxin play an important role in host plant with pathogen interaction. Many fungus were reported to produce a toxin secondary metabolites in to the media (Agrios 2004). Toxin studies were carried out by introducing the fungal growth filtrate on to the maize plants. Two methods were used spray method and pin prick method. Necrosis is a form of cell injury which results in the pre mature death of cells in living tissues by auto lysis. It is caused by external factors such as infection, toxin or trauma which results in unregulated digestion of cell components. Necrosis is always detrimental and can be fatal. Cellular death due to necrosis doesn't follow the apoptotic signal transduction pathway but various receptors are activated and results in the rest of cell membrane integrity and uncontrolled release of product of cell death into the extra cellular space. Necrosis was rated on scale of 0-72 hours. Chlorosis is a condition in which leaves produce insufficient chlorophyll. As chlorophyll is responsible for the green color of leaves; chlorotic leaves are pale, yellow, or yellow-white. The affected plant has little or known ability to manufacture carbohydrates through photosynthesis and may die unless the cause of its chlorophyll insufficiency is treated. Chlorosis is typically caused when leaves do not have enough nutrients to synthesize all the chlorophyll they need. According to the observations, the spray and pin-prick method showed best results. After 24 hours the sprayed leaves showed wilting and after 2-3 days the leaves withered. In present investigation Helminthosporium pathovars found to release toxic metabolites in to the medium that was extracts from culture filtrate. Similar results were obtained for isolated toxin from the culture filtrate of $D$. maydis and induced necrosis and chlorosis on Costusspeciosus leaves followed by yellowing and defoliation (Janardhana et.al 1981). Kramer et al. in their study found that partially purified toxin preparation from culture filtrate of the pathogen $D$. teres caused concentrated specific necrotic lesions on leaf tips and margins of susceptible genotypes of barley (1989).Methanol and chloroform solvents were used for the extraction of toxin from culture filtrate. Methanol and chloroform proven to beneficial solvent for the extraction of toxin from culturefiltrate proved in earlier report (Lanigan et.al 1979). The usage of thin layer chromatography to detect, identify and partially purify many mycotoxins(Scott.et.al 1970). Crude toxin solution silica sheets developed with the solvent system of Chloroform: Methanol (6.0:4.0) produced the best separation of toxin solution. Where in 2 spots / bands of light yellow colour were observed on the silica sheets.

\section{Conclusion}

In the Present investigation pathovars isolated from infected samples of maize was helminthosporium and PDA and MRBA was the best suitable media for the growth. And its growth was found to be good at optimum temperature of $20^{\circ}$ and $25^{\circ}$, pH of 5 and 6 with best carbon source such as starch and glucose. The study also reveals the production secondary metabolites from culture filtrate.

\section{References}

[1] Thompson DL, Bergquest RR (1984). Inheritance of mature plant resistance to helmintosporium maydis race $O$ inmaize. Crop Sci. 24:807 -811.

[2] Kump, K.L., Bradbury, P.J., Wisser, R.J., Buckler, E.S., Belcher, A.R., Oropeza-Rosas, M.A., Zwonitzer, J.C., Kresovich, S., McMullen, M.D. and Ware, D. (2011) Genome-Wide Association Study of Quantitative Resistance to Southern Leaf Blight in the Maize Nested Association Mapping Population. Nature genetics, 43, 163168.

[3] Holley, R. and Goodman, M. (1989) New Sources of Resistance to Southern Corn Leaf Blight from Tropical Hybrid Maize Derivatives. Plant disease, 73, 562-564.

[4] Smith, D., Hooker, A. and Lim, S. (1970) Physiologic Races of Helminthosporium maydis. Plant Disease Reporter, 54, 819-822.

[5] Wei, J.-K., Liu, K.-M., Chen, J.-P., Luo, P.C. And Stadelmann, O. (1988) Pathological and PhysiologicalIdentification of Race $\mathrm{C}$ of Bipolaris maydis in China. Phytopathology, 78, 550-554.

[6] Gao L, Liu X. Nutritional requirement of mycelial growth and sporulation of several biocontrol fungi in submerged and on solid culture. Microbiology. 2010; 79(5):622-29.

[7] Kumar S, Rani A. (2009). Cultural and nutritional studies in relation to growth and sporulation of Helminthosporium maydis. Ann of Plant ProtSci; 17(1):251-52

[8] Amin N, Nasruddin A, Daha L (2012). Isolation, Identification and in-vitro screening of fungal endophytes against pathogen of Maize leaf blight, Helminthosporium Maydis. The 21st National Congress of the Indonesian Phytopathol Soc.

[9] Didvania S, Shah R, Jadon KS (2012). A new disease of 


\section{International Journal of Science and Research (IJSR) \\ ISSN (Online): 2319-7064 \\ Index Copernicus Value (2015): 78.96 | Impact Factor (2015): 6.391}

Bell Pepper (Capsicum annuum var. grossum) caused by Drechslera bicolor, its pathophysiology, efficacy of fungicides and botanicals. Plant Pathol. J.; DOI: 10.3923.

[10] Wallin JR, Loonan DV (1977). Temperature and humidity associated with sporulation of $H$. maydis race $\mathrm{T}$. Phytopathol; 67:1370-72.

[11]Chandwani G H and Munjal R L (1963).studies on Physiology of Helminthosporium gramineumRab.,the causal agent of stripe disease of barle.Indianphytopath 16,301-306.

[12] Misra a P., and singh s p (1963).effect of Temperature and Humidity on the development of Helminthosporiumturcicumpass. Indian Phytopath.

[13] Singh GP, Singh B (1966). A leaf spot disease of maize caused by Bipolaris maydis (Nisikado) Shoemaker. Procduction of Natural Acadmey of Science India. Section. 36:303-05.

[14] Agrios GN (2004) Plant Pathology. 4th ed. Academic Press, New York, USA, ISBN: 0120445654

[15] Janardhanan KW, Gupta ML, Hussain A (1981). Isolation of a phytotoxic metabolite produced by Drechslera maydis (Nis) Subra causing leaf blight of Costusspeciosus (Koen.) Sm. PhytopatholMediterr. 20:13-16.

[16] Kramer RM, Opel M, Siebert A (1989). Response of detached barley leaves to partially purified toxin preparation of Drechslerateres(Sacc.) shoem. Archiv. Phytopathol. Pflanz. 25: 277-283.

[17] Lanigan GW, Payne AL, et al. (1979) Phomopsin A production by Phomopsisleptostromiformis in liquid media. Appl. Environ. Microbiol. 37(2): 289-292.

[18] Scott PM, Lawrence JW, et al. (1970) Detection of mycotoxins by thin-layer chromatography: application to screening of fungal extracts. Appl. Microbiol. 20(5): 839842. 